University of Nebraska - Lincoln

DigitalCommons@University of Nebraska - Lincoln

\title{
Simulated Rainfall-Driven Dissolution of TNT, Tritonal, Comp B and Octol Particles
}

\author{
Susan Taylor \\ Cold Regions Research and Engineering Laboratory, 72 Lyme Road, Hanover, NH \\ James H. Lever \\ Cold Regions Research and Engineering Laboratory, 72 Lyme Road, Hanover, NH \\ Jennifer Fadden \\ Cold Regions Research and Engineering Laboratory, 72 Lyme Road, Hanover, NH \\ Nancy Perron \\ Cold Regions Research and Engineering Laboratory, 72 Lyme Road, Hanover, NH \\ Bonnie Packer \\ US Army Environmental Command, Hoadley Road, Aberdeen Proving Ground, MD 21010, United States
}

Follow this and additional works at: https://digitalcommons.unl.edu/usarmyresearch

Part of the Operations Research, Systems Engineering and Industrial Engineering Commons

Taylor, Susan; Lever, James H.; Fadden, Jennifer; Perron, Nancy; and Packer, Bonnie, "Simulated RainfallDriven Dissolution of TNT, Tritonal, Comp B and Octol Particles" (2009). US Army Research. 52.

https://digitalcommons.unl.edu/usarmyresearch/52

This Article is brought to you for free and open access by the U.S. Department of Defense at DigitalCommons@University of Nebraska - Lincoln. It has been accepted for inclusion in US Army Research by an authorized administrator of DigitalCommons@University of Nebraska - Lincoln. 


\title{
Simulated rainfall-driven dissolution of TNT, Tritonal, Comp B and Octol particles
}

\author{
Susan Taylor ${ }^{\mathrm{a}, *}$, James H. Lever ${ }^{\mathrm{a}}$, Jennifer Fadden ${ }^{\mathrm{a}}$, Nancy Perron ${ }^{\mathrm{a}}$, Bonnie Packer ${ }^{\mathrm{b}}$ \\ ${ }^{a}$ Cold Regions Research and Engineering Laboratory, 72 Lyme Road, Hanover, NH 03755-1290, United States \\ ${ }^{\mathrm{b}}$ US Army Environmental Command, Hoadley Road, Aberdeen Proving Ground, MD 21010, United States
}

\section{A R T I C L E I N F O}

\section{Article history:}

Received 7 October 2008

Received in revised form 8 January 2009

Accepted 9 January 2009

Available online 11 February 2009

\section{Keywords:}

Dissolution model

High explosives

Laboratory drip tests

TNT

Comp B

\begin{abstract}
A B S T R A C T
Live-fire military training can deposit millimeter-sized particles of high explosives (HE) on surface soils when rounds do not explode as intended. Rainfall-driven dissolution of the particles then begins a process whereby aqueous HE solutions can enter the soil and groundwater as contaminants. We dripped water onto individual particles of TNT, Tritonal, Comp B and Octol to simulate how surface-deposited HE particles might dissolve under the action of rainfall and to use the data to verify a model that predicts HE dissolution as a function of particle size, particle composition and rainfall rate. Particle masses ranged from 1.1 to $17 \mathrm{mg}$ and drip rates corresponded to nominal rainfall rates of 6 and $12 \mathrm{~mm} \mathrm{~h}^{-1}$. For the TNT and Tritonal particles, TNT solubility governed dissolution time scales, whereas the lower-solubility of RDX controlled the dissolution time of both RDX and TNT in Comp B. The large, low-solubility crystals of HMX slowed but did not control the dissolution of TNT in Octol. Predictions from a drop-impingement dissolution model agree well with dissolved-mass timeseries for TNT, Tritonal and Comp B, providing some confidence that the model will also work well when applied to the rainfall-driven, outdoor dissolution of these HE particles.
\end{abstract}

\section{Introduction}

Military ranges provide soldiers the opportunity to train using a variety of munitions. However, live-fire training can deposit high explosives (HE) such as 2,4,6-trinitrotoluene (TNT), 1,3,5-hexahydro-1,3,5-trinitrotriazine (RDX) and octahydro-1,3,5,7-tetranitro1,3,5,7-tetrazocine (HMX) on the range. Detonations scatter HE particles broadly over surface soils. High-order detonations scatter $\mu \mathrm{m}$-size HE particles and low-order (LO) detonations scatter mmto-cm-sized HE particles (Taylor et al., 2006). Given the low drinking water screening levels for TNT $\left(2.2 \mu \mathrm{g} \mathrm{L}^{-1}\right)$ and RDX $\left(0.6 \mu \mathrm{g} \mathrm{L}^{-1}\right)$ ( EPA, 2008) gram-to-kilogram quantities of these explosives in aqueous solution may contaminate an aquifer, as occurred at the Massachusetts Military Reservation (Clausen et al., 2006). The low drinking water levels reflect their toxicity to human health (ATSDR, 1995).

Range characterization studies summarized by Pennington et al. (2006) found HE in surface soils at all 27 military installations sampled and HE was found in groundwater at Fort Lewis WA (Jenkins et al., 2001), and at three Canadian installations (Martel et al., 1999; Pennington et al., 2006). Dissolution of HE particles by precipitation has to occur before aqueous transport or bio-degradation of the HE. Therefore dissolution rates of HE particles as a function

\footnotetext{
* Corresponding author. Tel.: +1 603646 4239; fax: +1 6036464785 .

E-mail address: Susan.Taylor@usace.army.mil (S. Taylor).
}

of particle size, composition and rainfall rate are needed to predict HE aqueous influx to surface soils at training ranges.

Lynch et al. (2002a,b) and Phelan et al. (2003) conducted, respectively, stirred-bath and glass-bead-column experiments to measure the aqueous dissolution rates of collections of HE particles. We followed the method described in Lever et al. (2005) and dripped water on individual, field-collected, mm-sized particles of four common high-explosive formulations: TNT, Tritonal (80:20 mix of TNT and aluminum flakes), Composition B (59:39:1 mix of RDX:TNT:wax) and Octol (70:30 mix of HMX:TNT). These are all melt cast explosives where aluminum, RDX and HMX crystals are added to molten TNT. The experiments simulated the rainfall-driven dissolution of HE particles scattered on surface soils. We then used the resulting dissolved-mass timeseries to validate a drop-impingement dissolution model developed for Comp B (Lever et al., 2005). By expanding the types of HE formulations tested and using two simulated rainfall rates, our intention was to improve confidence in the model's predictions of rainfall-driven, dissolution of HE particles on training ranges.

\section{Experimental methods}

\subsection{HE Particle samples}

TNT is a single-component explosive, as is Tritonal albeit with $20 \%$ aluminum flakes, while Comp B and Octol are two-component 
explosives. We tested two particles for each HE formulation, all collected from training ranges. The TNT samples were collected after a LO detonation of a $155-\mathrm{mm}$ round, the Comp B samples were from the LO detonation of an 81-mm round, and the Tritonal samples were from a LO detonation of a 230-kg (500-lb) bomb. We obtained a single Octol particle from soils sampled on an anti-tank firing range and split it to form the two samples tested here.

Before starting the drip experiments, we individually weighed the dry HE particles on a Mettler Toledo MX5 microbalance (uncertainty $\pm 0.01 \mathrm{mg}$ ) and photographed them using a camera attached to a binocular microscope. Part way through the tests, we re-photographed the particles to document changes to their appearance.

Lever et al. (2005) showed that mm-sized Comp B detonation residues varied substantially in their RDX/TNT ratios, averaging $1.74 \pm 0.28$ ( \pm 1 standard deviation) compared with a nominal composition of $60 / 39=1.54$. Significant deviations in composition are likely for field-recovered HE particles with component crystals that are large compared with overall particle size. To measure this variability for Tritonal, we weighed $21 \mathrm{~mm}$-sized particles on a Sartorius electronic balance (uncertainty $\pm 0.1 \mathrm{mg}$ ), dissolved them in acetonitrile and analyzed their TNT compositions. We did not have sufficient Octol to investigate variability in Octol particle compositions.

\subsection{Laboratory setup}

Two Cole Palmer multi-syringe pumps allowed us to drip deionized water simultaneously onto eight separate particles, two particles for each of the four HE formulations at two different drip rates. A needle on each syringe dripped water onto an HE particle resting on a 10 -mm-diameter glass frit at the base of a Buchner funnel that drained into a 20 - or $40-\mathrm{mL}$ scintillation vial. The vials were replaced daily and the volume and HE concentration of the effluent analyzed. These data provided dissolved HE mass as a function of time for each of the eight particles. At the end of the tests, we extracted each frit and funnel with acetonitrile and analyzed the solutions for HE mass.

The programmed flow rates for each pump were 0.5 and $1.0 \mathrm{~mL} \mathrm{~h}^{-\mathbf{1}}$. We measured the actual flow rates and number of drops per hour for each syringe. These averaged $0.47 \pm$ $0.06 \mathrm{mLh}^{-1}$ with 26 drops $\mathrm{h}^{-1}$ and $0.95 \pm 0.09 \mathrm{~mL} \mathrm{~h}^{-1}$ with 56 drops $h^{-1}$ at the two, programmed rates. For reference, these flow rates correspond to rainfall rates of 5.9 and $12.0 \mathrm{~mm} \mathrm{~h}^{-1}$ based on the cross-sectional area of each glass frit. The average volume of the arriving drops was larger than that expected for the natural rainfall at the same rates (Pruppacher and Klett, 1997) and each arriving drop wetted the particle on the frit. The de-ionized water used for the tests was at room temperature and the latter was fairly constant throughout the tests at $22 \pm 1{ }^{\circ} \mathrm{C}$. The tests were normally halted over the weekends and the particles allowed to dry.

\subsection{Analytical methods}

Explosive concentrations were determined following SW-846 Method 8330B (EPA, 2006). One $\mathrm{mL}$ of the effluent was added to $2 \mathrm{~mL}$ of de-ionized water and to $1 \mathrm{~mL}$ of acetonitrile and then filtered through a $0.45 \mu \mathrm{m}$ Millipore syringe filter. High Performance Liquid Chromatography separated TNT, RDX, HMX, and their cocontaminants and breakdown products. We used a Waters NovaPak C8 column (3.9 mm by $150 \mathrm{~mm}$ ) eluted at $1.4 \mathrm{~mL} \mathrm{~min}^{-1}\left(28^{\circ} \mathrm{C}\right)$ with $85: 15$ water:isopropanol mix and detected by UV at $254 \mathrm{~nm}$. A commercially available standard (Restek) was used for calibration. We prepared 1-ppm and 10-ppm dilutions of these standards. The $1 \mathrm{ppm}$ standards were run every ten samples and blanks were run before and after each standard run. The $10 \mathrm{ppm}$ standards were interspersed with the samples as internal checks, with blanks after each to prevent carryover. Based on the concentrations of the standards and the precision of the effluent volumes, we estimate that the cumulative dissolved HE masses have uncertainties of about $\pm 1 \%$.

\section{Results}

\subsection{He mass recovery}

We analyzed 21 Tritonal particles for compositional variability. The percentage of TNT by weight ranged from $52 \%$ to $84 \%$ of particle mass and averaged $77.5 \% \pm 6.6 \%$. Thus, the average of the 21 particles fell well within 1 standard deviation of the nominal composition of Tritonal (80\% TNT).

Table 1 lists the dissolution test parameters and the recovered mass for the eight drip test particles. The nominal drip rates were $0.5 \mathrm{~mL} \mathrm{~h}^{-1}$ and $1.0 \mathrm{~mL} \mathrm{~h}^{-1}$ for the " 1 " and " 2 " particle designations, respectively. We recovered essentially $100 \%$ of the mass for the two TNT particles and for Comp B 2. The recovered HE mass for Comp B 1 (96.5\%) was close to the average ( $96 \% \pm 1 \%$ ) found by Lever et al. (2005) for 30 individual Comp B particles obtained from the same low-order detonation. The two particles dissolved here had RDX/TNT ratios of 1.69 and 1.87 , similar to the average ratio obtained by Lever et al. (2005) of $1.74 \pm 0.28$. We measured less than $1 \%$ HMX, an impurity in RDX, in these Comp B particles.

The recovered TNT mass was $67.8 \%$ and $78.5 \%$ of the initial mass for Tritonal 1 and Tritonal 2, respectively. This included TNT extracted from the frits. Both particles fell within $2 \sigma$ of the nominal Tritonal composition. Aluminum grains constituted the remaining mass for the Tritonal particles.

For Octol 1 and Octol 2, we recovered $1.86 \mathrm{mg}$ and $3.61 \mathrm{mg}$ of TNT, representing $28.4 \%$ and $20.8 \%$ of the initial particle masses, respectively. Octol nominally contains $30 \%$ TNT, but we would expect millimeter-sized particles to vary significantly from this value owing to the large $(\sim 1 \mathrm{~mm})$ crystals of HMX present in the TNT matrix. Both dissolution tests continued for many days with

Table 1

Dissolution test parameters and the recovered mass for HE particles.

\begin{tabular}{|c|c|c|c|c|c|}
\hline Particle & Drip rate $\left(\mathrm{mL} \mathrm{h}^{-1}\right)$ & Initial mass (mg) & Dissolved-mass (mg) & Time (days) & $\%$ Mass recovered \\
\hline TNT 1 & 0.5 & 5.34 & 5.33 & 201 & 99.9 \\
\hline TNT 2 & 1.0 & 9.59 & 9.70 & 98 & 101 \\
\hline Tritonal 1 & 0.5 & 1.89 & 1.28 & 72 & $67.8^{*}$ \\
\hline Tritonal 2 & 1.0 & 6.40 & 5.02 & 73 & $78.5^{*}$ \\
\hline Comp B 1 & 0.5 & 2.31 & 2.23 & 200 & 96.5 \\
\hline Comp B 2 & 1.0 & 9.09 & 9.03 & 141 & 99.4 \\
\hline Octol 1 & 0.5 & 6.53 & 2.15 & 101 & $33.9^{*}$ \\
\hline Octol 2 & 1.0 & 17.33 & 9.92 & 140 & $57.2^{*}$ \\
\hline
\end{tabular}

All the TNT mass. 

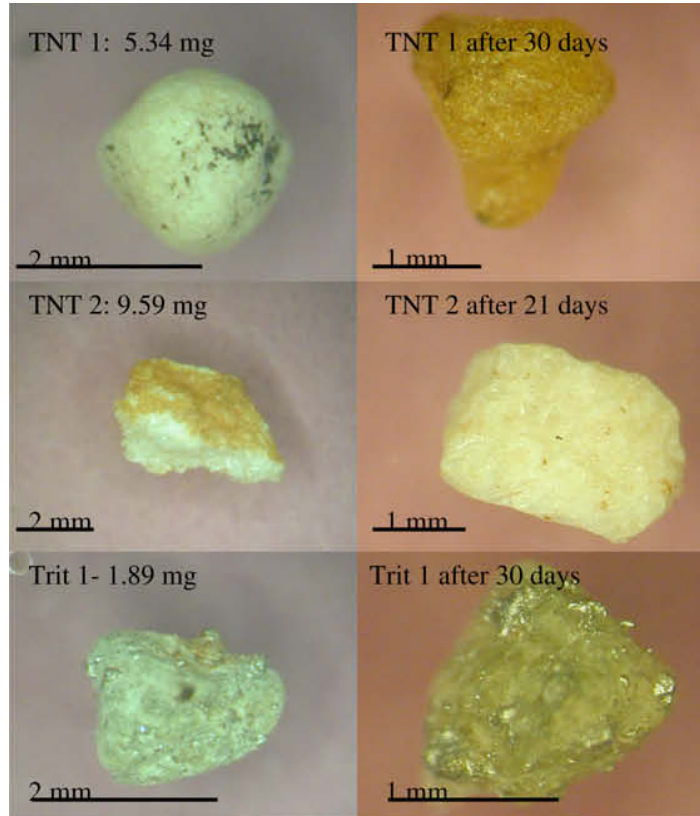

TNT 2 after 21 days

Trit 2- $6.40 \mathrm{mg}$

Trit 2 after 21 days

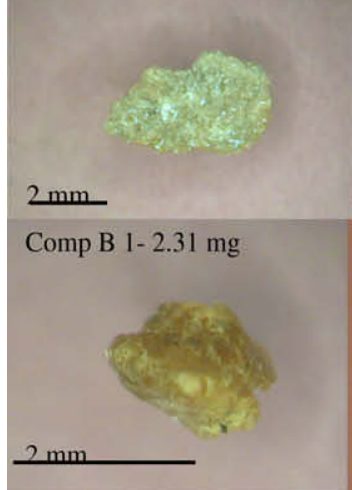

Trit 1 after 30 days
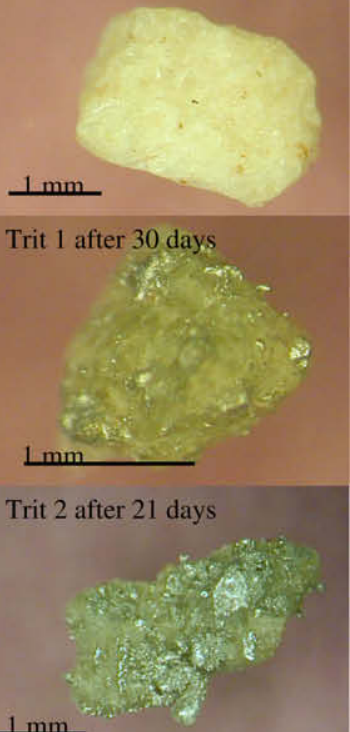

$1 \mathrm{~mm}$
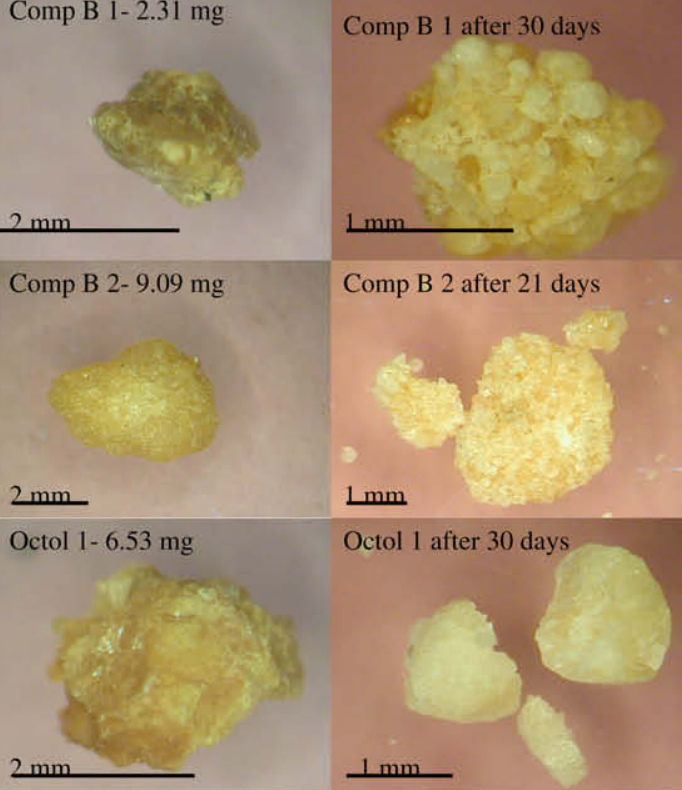

Octol 2- $17.33 \mathrm{mg}$

Octol 2 after 21 days

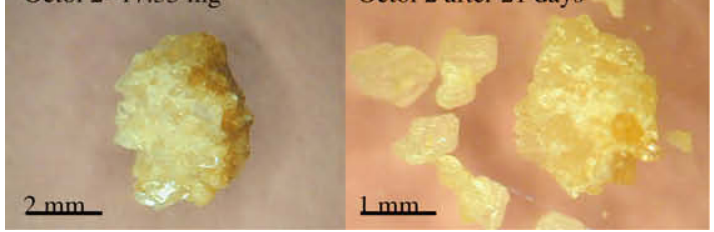

Fig. 1. Photos and initial masses of mm-sized particles used in the laboratory tests paired with photos of the same particle taken partway through the tests.

no measurable TNT in the water samples, and we found no additional TNT in a series of acetonitrile extractions of the funnels and frits at the end of the tests. Thus, we think that the dissolution tests recovered all the TNT initially present in the two Octol particles.

\subsection{Appearance of test particles}

Fig. 1 shows photographs of the 8 particles taken at the beginning and partway through the dissolution tests, at 30 days for the $0.5 \mathrm{~mL} \mathrm{~h}^{-1}$ tests and at 21 days for the $1.0 \mathrm{~mL} \mathrm{~h}^{-\mathbf{1}}$ tests. The TNT particles became smoother and smaller but retained their original shapes. The Tritonal particles became smaller and slightly bumpier as TNT dissolved exposing the aluminum grains. The Comp B particles, on the hand, became noticeably bumpier and 'sugary' looking as dissolution of the surface TNT revealed the larger ( $0.1 \mathrm{~mm}$ ), slower-dissolving RDX crystals. The Octol particles disaggregated completely when their TNT matrix dissolved leaving large ( 1 mm) HMX crystals (see Fig. 1, Octol 2 at $21 \mathrm{~d}$ ).

\subsection{Dissolution modeling and comparison with dissolved-mass timeseries}

Lever et al. (2005) developed and validated a drop-impingement model for the rainfall-driven dissolution of mm-sized Comp B particles. It pertains to the practical case where spatially isolated HE particles reside on well-draining surface soils and thus are exposed to direct impingement by raindrops. The present experiments simulated these circumstances. With rare exceptions, water quickly drained through the glass frits so that impinging drops interacted directly with the HE particles. The present experiments offer additional data to validate this model for other HE formulations and for two simulated rainfall rates.

The drop-impingement dissolution model assumes that raindrops hit and wet an HE particle. Between raindrops, the particle holds a stagnant water-layer against its surface, which saturates, via diffusion, with HE. Arrival of the next raindrop washes away the dissolved HE and refreshes the stagnant layer. The dissolution rate, $m_{j}\left(\mathrm{~g} \mathrm{~s}^{-\mathbf{1}}\right)$ of HE species $j$, averaged over a drop-arrival interval, $t_{d}(\mathrm{~s})$, is thus

$m_{j}=\frac{S_{j} V_{l}}{t_{d}}$

where $S_{j}$ is the solubility of species $j$ in water $\left(\mathrm{g} \mathrm{cm}^{-3}\right)$ and $V_{1}$ is the water-layer volume $\left(\mathrm{cm}^{3}\right)$. For a spherical particle, a water-layer of thickness $h(\mathrm{~cm})$ will effectively saturate (average concentration $>0.9 S_{j}$ ) provided

$t_{d}>\frac{h^{2}}{D_{j}} \equiv t_{s}$

where $D_{j}$ is the diffusion coefficient of species $j$ into water $\left(\mathrm{cm}^{2} \mathrm{~s}^{-\mathbf{1}}\right)$ and $t_{s}$ defines the layer saturation time. Additionally, for Eq. (1) to apply, the volume of an arriving water drop, $V_{d}$, must be larger than the volume of the stagnant water-layer, which generally limits its applicability to mm-sized and smaller particles.

Each HE species in a particle could dissolve independently, following Eq. (1), if it is in contact with the water-layer and has a sufficiently high diffusion coefficient to satisfy Eq. (2). However, Comp $\mathrm{B}$ and Octol particles consist of low-solubility crystals (RDX and HMX, respectively) embedded in higher-solubility TNT matrixes. Initially, TNT on the surface of these particles can dissolve independently into the water-layer, leading to high initial TNT dissolution rates. However, the lower-solubility crystals eventually restrict the pathways for TNT molecules to diffuse into the water-layer. TNT diffusion into the layer then becomes analogous to molecular diffusion through a porous medium, where porosity and tortuosity combine to reduce significantly the effective diffusion coefficient 
Table 2

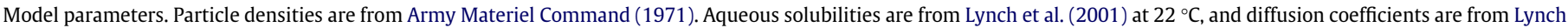

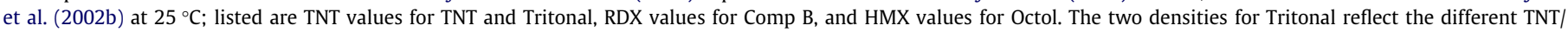
aluminum ratios of the two particles.

\begin{tabular}{|c|c|c|c|c|c|c|c|}
\hline Particle & $\rho\left(\mathrm{g} \mathrm{cm}^{-3}\right)$ & $S_{j}\left(\mathrm{~g} \mathrm{~cm}^{-3}\right)$ & $D_{j}\left(\mathrm{~cm}^{2} \mathrm{~s}^{-1}\right)$ & $t_{d}(\mathrm{~s})$ & $h(\mathrm{~mm})$ & $t_{s}(\mathrm{~s})$ & $V_{d} / V_{1}$ \\
\hline TNT 1 & 1.65 & $1.17 \mathrm{E}-04$ & $6.71 \mathrm{E}-06$ & 138 & 0.075 & 8.4 & 21 \\
\hline TNT 2 & 1.65 & $1.17 \mathrm{E}-04$ & $6.71 \mathrm{E}-06$ & 64 & 0.095 & 13 & 10 \\
\hline Tritonal 1 & 1.89 & $1.17 \mathrm{E}-04$ & $6.71 \mathrm{E}-06$ & 138 & 0.090 & 12 & 35 \\
\hline Tritonal 2 & 1.80 & $1.17 \mathrm{E}-04$ & $6.71 \mathrm{E}-06$ & 64 & 0.082 & 10 & 17 \\
\hline Comp B 1 & 1.65 & $4.02 \mathrm{E}-05$ & $2.20 \mathrm{E}-06$ & 138 & 0.092 & 38 & 28 \\
\hline Comp B 2 & 1.65 & $4.02 \mathrm{E}-05$ & $2.20 \mathrm{E}-06$ & 64 & 0.110 & 55 & 9.1 \\
\hline Octol 1 & 1.80 & $3.64 \mathrm{E}-06$ & $1.50 \mathrm{E}-04$ & 138 & 0.12 & 1.0 & 12 \\
\hline Octol 2 & 1.80 & $3.64 \mathrm{E}-06$ & $1.50 \mathrm{E}-04$ & 64 & 0.19 & 2.4 & 3.5 \\
\hline
\end{tabular}
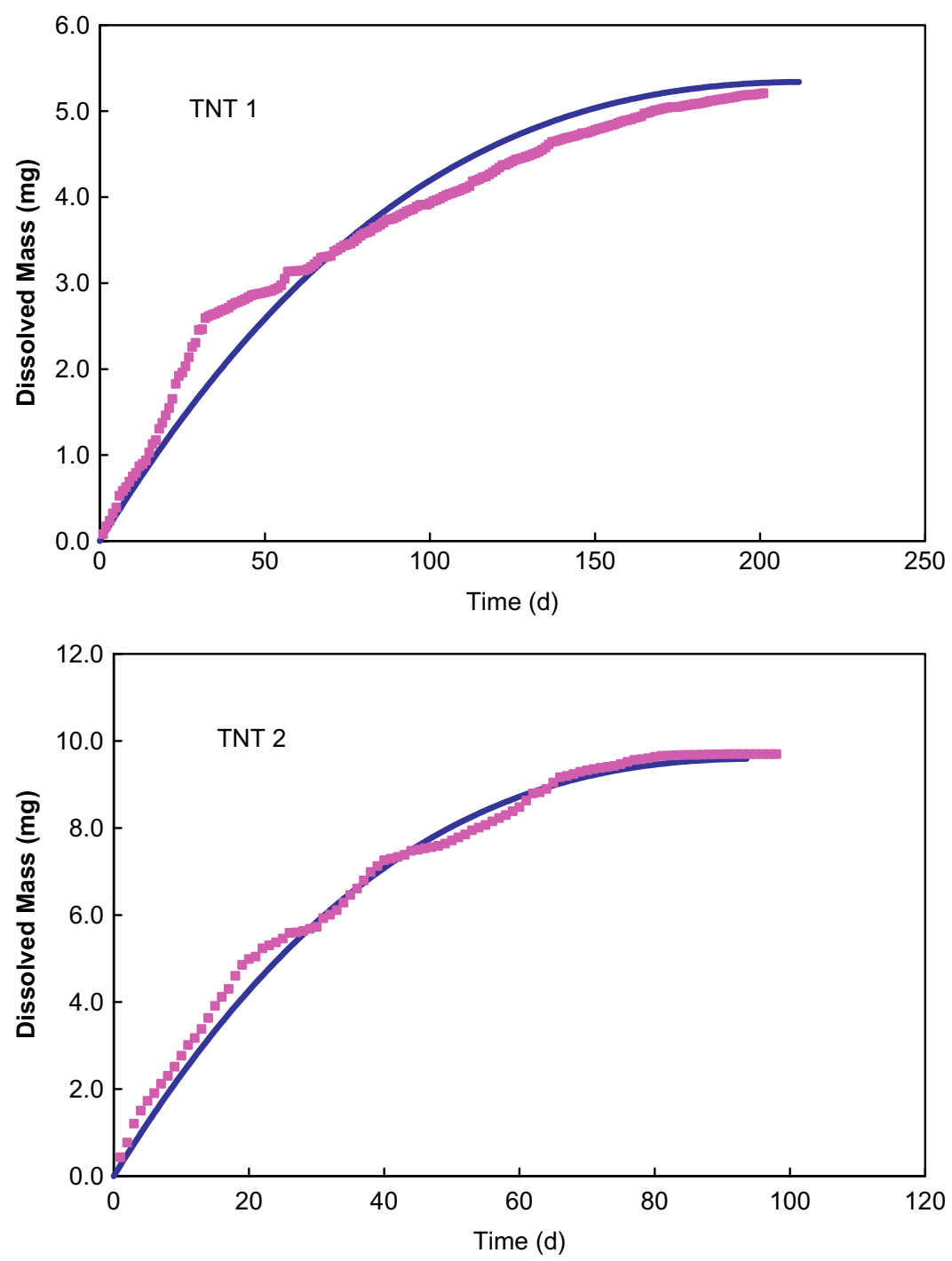

Fig. 2. Dissolved-mass versus time for the TNT test particles (symbols are measured values, smooth curves are modeled values).

(Bear, 1972; Chambre and Pigford, 1984). Consequently, TNT will not saturate the water-layer between drops and its effective dissolution rate will decrease.

Lever et al. (2005) observed this effect during laboratory drip tests of Comp B particles. They implemented the limiting case where RDX dissolution controls the dissolution of TNT by using Eq. (1) for RDX and assuming that TNT dissolves at a rate that maintains the bulk RDX/TNT mass ratio:
$m_{\mathrm{TNT}}=m_{\mathrm{RDX}} \frac{\rho_{\mathrm{TNT}}}{\rho_{\mathrm{RDX}}}$

where $\rho_{\mathrm{TNT}}$ and $\rho_{\mathrm{RDX}}$ are the mass densities of each species in the original Comp B particle. This approach ensured that the time scale for RDX dissolution controlled the predicted TNT dissolution rate. We applied this approach for both Comp B and Octol particles, substituting $\rho_{\mathrm{HMX}}$ for $\rho_{\mathrm{RDX}}$ in Eq. (3) for Octol. 
We implemented the drop-impingement model for the eight test particles by treating each particle as a sphere of equivalent mass, so that the water-layer volume is simply

$V_{l}=\frac{4}{3} \pi\left[(a+h)^{3}-a^{3}\right]$

where $a$ is sphere radius $(\mathrm{cm})$. Because we could not measure the water-layer thicknesses, we determined $h$ by fitting the predictions to the measured dissolved-mass timeseries for the slower-dissolving species in each particle. Effects of non-spherical particle shape are thereby folded into $h$. Table 2 summarizes the parameters needed to run the drop-impingement model and to check its validity $\left(t_{d}>t_{s}, V_{d}>V_{1}\right)$.

Figs. 2 and 3 show the measured and predicted dissolvedmasses for the TNT and Tritonal particles, respectively. These particles contain only TNT, so Eq. (1) applies directly. The model predicts the dissolution of all four particles quite well. The average layer thicknesses for the TNT and Tritonal particles were essentially the same at $0.085 \pm 0.014 \mathrm{~mm}$ and $0.086 \pm 0.006 \mathrm{~mm}$, respectively. Note that for the particles, the drop-arrival times were longer than the water-layer saturation times, and the drop volumes were larger than the water-layer volumes (Table 2 ) as required by Eq. (1).
Fig. 4 shows the measured and predicted dissolved-masses for the two Comp B particles. The predicted RDX dissolution agrees quite well with the measured results for both particles. In both tests, TNT initially dissolved quickly but eventually was controlled by the slower dissolution of RDX. The model predicts this behavior reasonably well using the limiting case of RDX control of TNT dissolution (Eq. (3)). By comparison, it predicts much faster dissolution under the assumption that TNT dissolves independently of RDX. Interestingly, the fastest dissolution rates observed near the beginning of the tests do approximate those for independent TNT dissolution. The transition from independent TNT dissolution to RDX-controlled dissolution probably reflects restriction of TNT diffusion into the water-layer by the porous medium of RDX crystals.

The fitted water-layer thicknesses average $0.101 \pm 0.013 \mathrm{~mm}$ for the two Comp B particles (Table 2). This compares well with the average value $(0.13 \pm 0.05 \mathrm{~mm})$ obtained for the four Comp $B$ particles tested by Lever et al. (2005). For both Comp B particles, the drop volumes were larger than the water-layer volumes, and the drop-arrival times were longer than the RDX saturation times (Table 2). TNT saturation times must increase to account for eventual RDX control of TNT dissolution.

Fig. 5 shows the measured and predicted dissolved-masses for the two Octol particles. As with Comp B, measured TNT dissolution
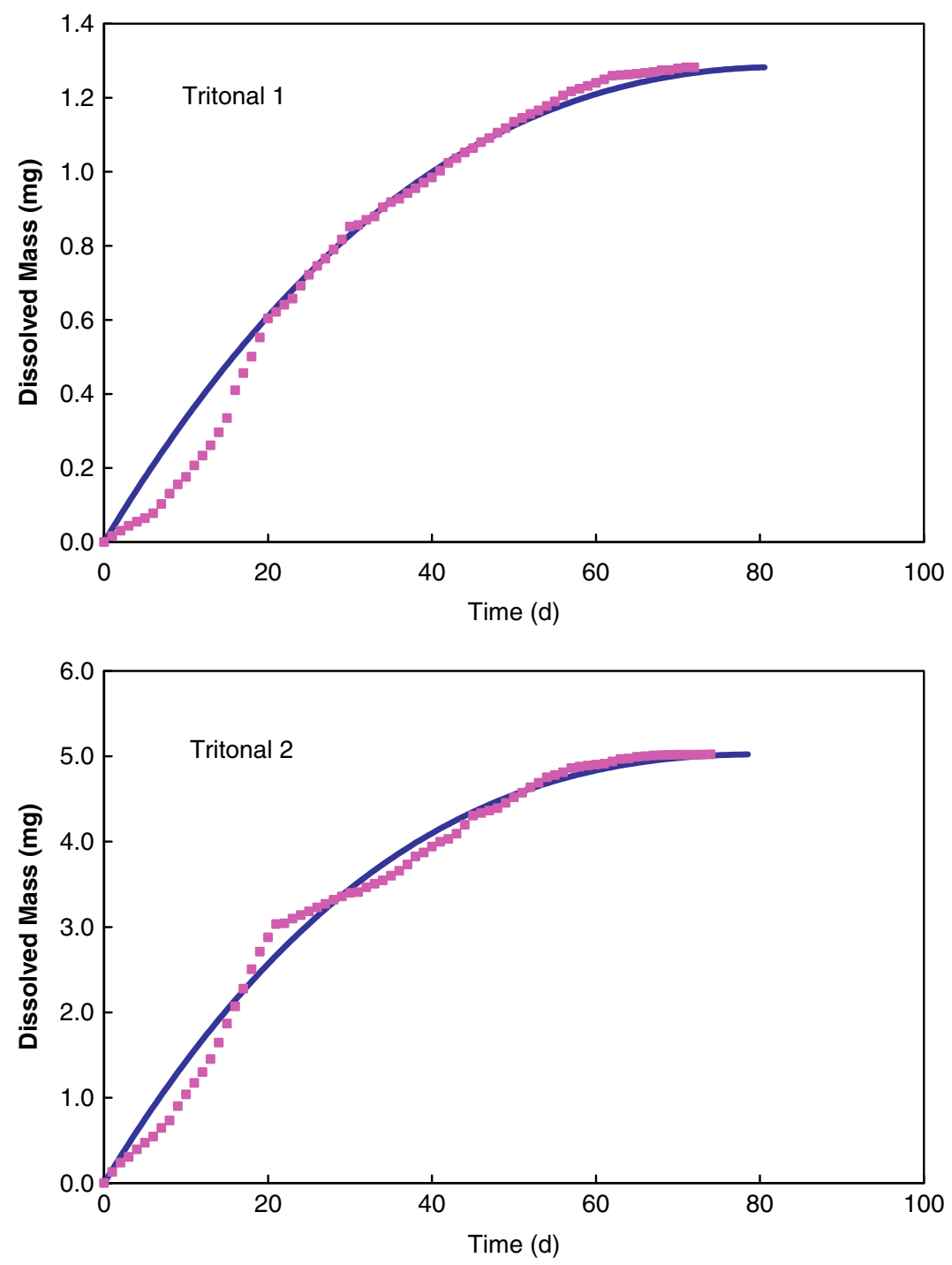

Fig. 3. Dissolved-mass versus time for the Tritonal test particles (symbols are measured values, smooth curves are modeled values). 

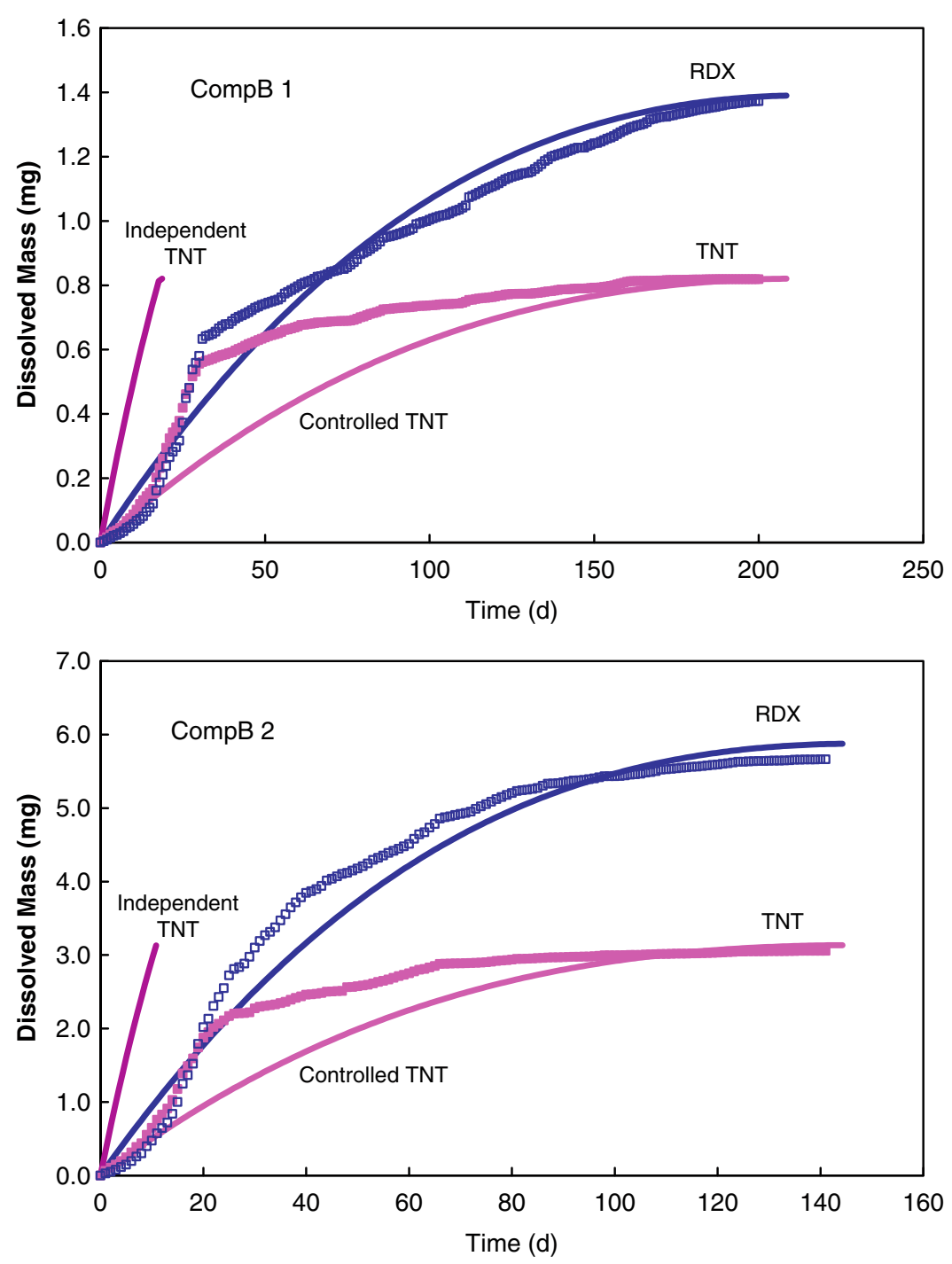

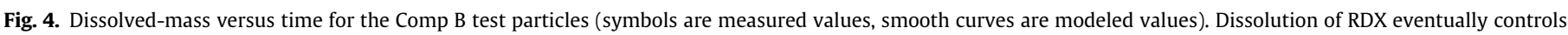
dissolution of TNT (modeled via Eq. (3)). Independent TNT dissolution would occur much faster.

initially proceeded quickly, with maximum dissolution rates approaching the predicted rates for independent TNT dissolution. Unlike Comp B, however, the larger HMX crystals did not eventually control TNT dissolution, and all the TNT dissolved from both particles, leaving HMX crystals. We terminated both tests after many days with no TNT in the water samples. The fitted waterlayer thicknesses averaged $0.155 \pm 0.049 \mathrm{~mm}$, much larger than those for the other particles (Table 2). Nevertheless, the calculated saturation times (Eq. (2)) based on either TNT or HMX diffusion were less than the drop-arrival times, and the water-film volumes were less than the drop volumes, as required by the model.

\section{Discussion}

The laboratory tests dripped water on individual HE particles collected from field detonations. They more closely simulate the physical circumstances of HE particles exposed to rainfall on surface soils than do stirred-bath (Lynch et al., 2002a,b) or glass-bead column experiments (Phelan et al., 2003). They yield estimates of aqueous HE influx to surface soils as functions of particle size, particle composition and rainfall rate while avoiding the complexity of aqueous-phase HE-soil interactions that occur during soil-column experiments (Pennington et al., 2006; Morley et al., 2006). TNT and RDX mass recoveries from all particles were very good; HMX mass recovery was complicated by its low-solubility and disaggregation of the Octol particles following complete TNT dissolution.

Changes in the appearance of the particles provided insight into their dissolution mechanics. The single HE-species particles, TNT and Tritonal, essentially retained their original morphologies as they dissolved, and their dissolution timeseries are fairly simple curves. The concentration of aluminum grains in Tritonal is apparently too low to disrupt dissolution of the TNT. By comparison, the Comp B and Octol particles quickly became lumpy as surface TNT dissolved to reveal underlying RDX and HMX crystals. Subsequently, the Comp B particles became smaller conglomerations of RDX crystals shielding internal TNT, while the Octol particles lost all their TNT and disaggregated into collections of HMX crystals.

We do not understand the reasons for discontinuities in the measured dissolution rates for some particles (e.g., TNT 1, Tritonal 2 and Comp B 1). The discontinuities do not coincide with the dates of particle removal for photographing or observed splitting of the particles, the good mass balances confirm that the particles did not lose pieces during handling, and several particles did not display discontinuities beyond random fluctuations.

The drop-impingement dissolution model predicts very well the dissolved-mass timeseries of the TNT and Tritonal particles. The 

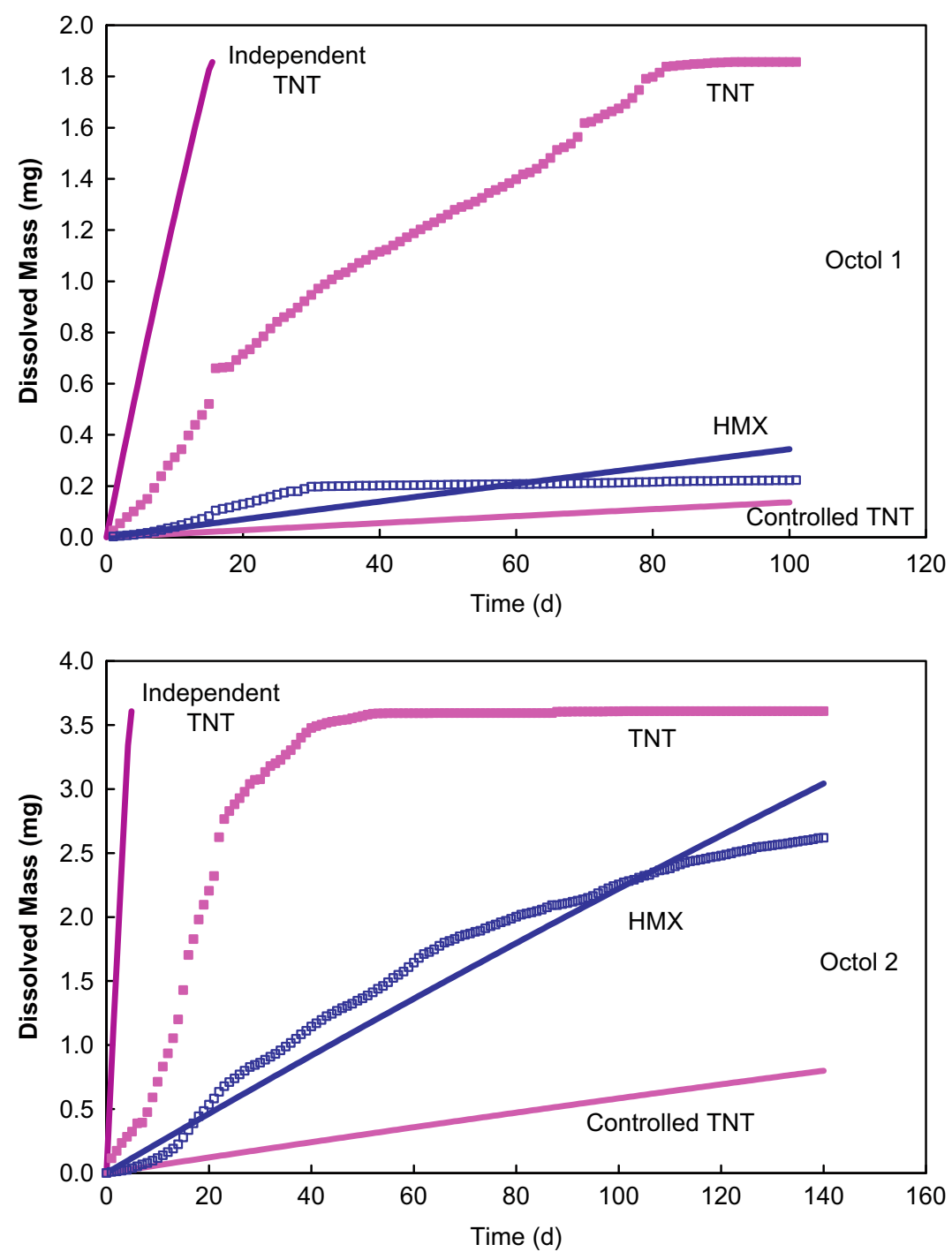

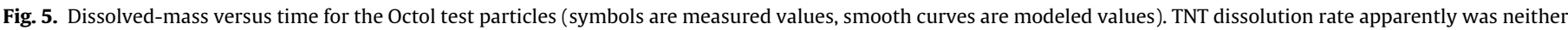
controlled by, nor independent of, HMX dissolution.

single tuning parameter, water-layer thickness, $h$, was reasonably consistent among the four particles, averaging $0.086 \pm 0.009 \mathrm{~mm}$. The model also predicts well the overall dissolution behavior of the Comp B particles and provides insight into the governing processes. Initially TNT dissolves independently of RDX, but increasing restriction of TNT diffusion by the RDX crystals eventually causes TNT dissolution to be controlled by RDX dissolution. With additional work, we hope to quantify this effect by modeling TNT diffusion within a changing porous RDX medium.

The model does not predict well the TNT dissolved-mass timeseries for the Octol particles. The large, low-solubility HMX crystals appeared to impede but not control TNT dissolution. That is, neither limiting model case (independent or HMX-controlled dissolution) fits the observed TNT data. The reduced influence of HMX on TNT dissolution, compared with the controlling role of RDX in Comp B, is consistent with less constraint of TNT diffusion into the surrounding water-layer. The higher fitted values of layer thickness $(0.155 \pm 0.049 \mathrm{~mm})$ could reflect the creation of surface area as the Octol particles disaggregated following TNT loss. These values give reasonable agreement to the limited HMX dissolution data, but more work is needed to quantify the impeding effect of HMX crystals on TNT dissolution in Octol.
The drop-impingement model accounts for differences in rainfall rates via differences in average drop-arrival time, $t_{d}$, in Eq (1). The generally good agreement between the observed and predicted dissolution data at two simulated rainfall rates suggests that $t_{d}$ does indeed scale dissolution rate.

We have initiated a series of outdoor dissolution tests where $\mathrm{cm}$-sized chunks of HE are exposed to natural weather conditions. These tests should closely simulate the dissolution of isolated HE pieces on range soils and provide a more realistic validation of the drop-impingement model. We are developing a "large-particle" version of the model to circumvent the restriction that raindrop volume be greater than water-film volume. Nevertheless, the model predicts quite well the dissolution of millimeter-size TNT, Tritonal and Comp B particles. This provides confidence it will also work well when applied to the rainfall-driven, outdoor dissolution of these HE materials.

\section{Acknowledgements}

We thank Dr. Jeffrey Marqusee and Dr. Andrea Leeson of the Strategic Environmental Research and Development Program (SERDP) for funding our project (ER-1482) and Carey Li and Pamela Collins for help running the laboratory tests. 


\section{References}

Army Materiel Command, 1971. Engineering Design Handbook: Explosives Series, Properties of Explosives of Military Interest. Army Materiel Command, Alexander, VA.

ATSDR, 1995. Toxicological profile for 2,4,6-trinitrotoluene and RDX. US Department of Health and Human Services, Public Health Service, Agency for Toxic Substances and Disease Registry, Atlanta, GA.

Bear, J., 1972. Dynamics of Fluids in Porous Media. Dover Publications, New York.

Chambre, P.L., Pigford, T.H., 1984. Prediction of waste performance in a geological repository. Mat. Res. Soc. Symp. Proc., Elsevier Science Publishing Co., vol. 26, 985-1008.

Clausen, J.L., Korte, N., Dodson, M., Robb, J., Rieven S., 2006. Conceptual Model for the Transport of Energetic Residues from Surface Soil to Groundwater by Range Activities. ERDC-CRREL TM-06-18.

Environmental Protection Agency, 2008. Region 6 Human Health Medium-Specific Screening Levels. www.epa.gov/Region6/6pd/rcra_c/pd-n/screen.htm.

Environmental Protection Agency, 2006. Nitroaromatics, Nitramines and Nitrate Esters by HPLC, SW-846 Method 8330B.

Jenkins, T.J., Pennington, J.C., Ranney, T.A., Berry Jr., T.E, Miyares, P.H., Walsh, M.E., Hewitt, A.D., Perron, N.M., Parker, L.V., Hayes C.A., Wahlgren E.G., 2001. Characterization of explosives contamination at military firing ranges, ERDC/ CRREL TR-01-5.

Lever, J., Taylor, S., Perovich, L., Bjella, K., Packer, B., 2005. Dissolution of Composition B Residuals. Environ. Sci. Technol. 39, 8803-8811.

Lynch, J.C., Myers, K.F., Brannon, J.M., Delfino, J.J., 2001. Effects of pH and temperature on the aqueous solubility and dissolution rate of TNT, RDX and HMX. J. Chem. Eng. Data 46, 1549-1555.
Lynch, J.C., Brannon, J.M., Delfino, J.J., 2002a. Effect of component interactions on the aqueous solubilities and dissolution rates of the explosive formulations Octol, Composition B and LX-14. J. Chem. Eng. Data 47, 542-549.

Lynch, J.C., Brannon, J.M., Delfino, J.J., 2002b. Dissolution rates of three high explosive compounds: TNT, RDX and HMX. Chemosphere 47, 725734

Martel R., Mailloux, M., Lefebvre, R., Michaud, Y., Parent, M., Ampleman, G., Thiboutot, S., Jean S., Roy N., 1999. Energetic materials behavior in groundwater at the Arnhem Anti-Tank Range, CFB Valcartier, Quebec, Canada. INRSGeoresources Report 1999-02.

Morley, M.C., Yamamoto, H., Speitel, G.E., Clausen, J., 2006. Dissolution kinetics of high explosives particles in a saturated sandy soil. J. Contam. Hydrol. 85, 141158 .

Pennington, J.C., Jenkins, T.F., Ampleman, G., Thiboutot, S., Brannon, J.M., Hewitt, A. D., Lewis, J., Brochu, S., Diaz, E., Walsh, M.R., Walsh, M.E., Taylor, S., Lynch, J.C., Clausen, J., Ranney, T.A., Ramsey, C.A., Hayes, C.A., Grant, C.L., Collins, C.M., Bigl, S.R., Yost, S., Dontsova K., 2006. Distribution and fate of energetics on DoD test and training ranges: final report. ERDC TR-06-13.

Phelan J.M., Webb, S.W. Romero, J.V. Barnett, Griffin F., Eliassi M., 2003. Measurement and Modeling of Energetic Material Mass transfer to Soil Pore Water-Project CP-1227. Sandia Report 2003-0153.

Pruppacher, H.R., Klett, J.D., 1997. Microphysics of Clouds and Precipitation. Kluwer Academic Publishers, Boston.

Taylor, S., Campbell, E., Perovich, L., Lever, J.H., Pennington, J., 2006. Characteristics of Composition B Particles from Blow-in-Place Detonations. Chemosphere 65, 1405-1413. 